\title{
The Effects of Respiratory Muscle Weakness and Pulmonary Involvement on Functional Status, Fatigue and Health Related Quality of Life in Patients With Systemic Sclerosis
}

\author{
Bilge KESİKBURUN, ${ }^{1}$ Belma Füsun KÖSEOĞLU, ${ }^{1}$ Ali ŞAHİN, ${ }^{2}$ Murat TURGAY, ${ }^{2}$ \\ Asuman DOĞAN, ${ }^{1}$ Öznur AYHAN ÖKEN ${ }^{1}$ \\ ${ }^{1}$ Department of Cardiopulmonary Rehabilitation Unit, Ankara Physical Medicine and Rehabilitation Training and \\ Research Hospital, Ankara, Turkey \\ ${ }^{2}$ Department of Rheumatology, Medical Faculty of Ankara University, Ankara, Turkey
}

\begin{abstract}
Objectives: The aim of this study is to investigate the effects of respiratory muscle strength and pulmonary involvement on functional status, fatigue, and health related quality of life (HRQoL) in patients with systemic sclerosis.

Patients and methods: Thirty-three patients ( 2 males, 31 females; mean age $46.2 \pm 13.4$ years; range 27 to 77 years) with systemic sclerosis and 34 healthy volunteers ( 3 males, 31 females; mean age $40.9 \pm 12.8$ years; range18 to 65 years) were included in the study. Pulmonary involvement and respiratory muscle strength were evaluated by measuring forced vital capacity, vital capacity, maximum voluntary ventilation, high resolution computed tomography, pulmonary artery systolic pressure, and visual analog scale for dyspnea. Functional status, HRQoL and fatigue were measured with Health Assessment Questionnaire Disability Index, Medical Outcomes Study Short Form-36 (SF-36), and Fatigue Severity Scale, respectively.

Results: Compared to healthy controls, our patients had lower functional status and HRQoL, and a higher fatigue level. Respiratory muscle strength had significant contribution on functional status and SF-36 physical component summary scores. Pulmonary arterial hypertension had significant predictive value for SF-36 physical component summary. Interstitial lung disease affected the functional status only. Dyspnea had significant predictive value for fatigue and mental component summary of SF-36.

Conclusion: Since a significant association is present between pulmonary involvement, respiratory muscle strength, functional status, HRQoL, and fatigue in patients with systemic sclerosis, these parameters should also be evaluated in the early period of the disease. Once respiratory muscle weakness and pulmonary involvement are detected in this population with limited treatment options, a comprehensive pulmonary rehabilitation program including respiratory muscle exercises should be designed to improve functional status, HRQoL, and fatigue.

Keywords: Pulmonary involvement; respiratory muscle weakness; systemic sclerosis.
\end{abstract}

Systemic sclerosis (SSc) is a chronic connective tissue disease of unknown etiology which causes widespread micro vascular damage, and excessive deposition of collagen in the skin and internal organs. Cardiopulmonary, renal and gastrointestinal system involvement, and organ based complications are frequent, and contribute to excess mortality and early morbidity. ${ }^{1-4}$

Systemic sclerosis affects the lung parenchyma (interstitial pulmonary fibrosis) or pulmonary blood vessels (pulmonary arterial hypertension) or both in the early stage of the disease. ${ }^{1,4-6}$ Lung fibrosis has been detected in approximately 70\% of SSc patients at autopsy. ${ }^{6,7}$ Also, pulmonary arterial hypertension is a common complication occurring in $15-20 \%$ of SSc patients. ${ }^{1,5,6}$

Symptoms of pulmonary involvement include dyspnea, fatigue, deconditioning, impaired exercise tolerance and in turn, reduced physical, recreational and social activities, and impaired health related quality of life (HRQoL). ${ }^{1,3,4,8-10}$ Studies on the contribution of pulmonary involvement and 
dyspnea to function and quality of life in patients with SSc have reported conflicting results. While some studies showed significant correlations, and advised that Short Form 36 (SF-36) and Health Assessment Questionnaire Disability Index (HAQ-DI) should be included as measurements in scleroderma lung disease, ${ }^{5,8}$ some studies did not detect a correlation, and concluded that these measurements are of no value in showing pulmonary involvement in these patients. ${ }^{1,9}$

Fatigue is increasingly recognized as an important and bothersome symptom in SSc patients. However, research investigating its correlation with pulmonary involvement and dyspnea in scleroderma lung disease is limited. ${ }^{2-4}$ Furthermore, to the best of our knowledge, no studies have been reported in the literature investigating the effect of respiratory muscle strength on functional status, HRQoL, and fatigue in SSc patients.

A proper understanding of the effects of respiratory muscle strength and pulmonary involvement on functional status, fatigue and HRQoL in SSc population can assist us in designing an effective and organized rehabilitation program, and promote an active life style in these patients. The aim of this study was to investigate the effects of respiratory muscle strength and pulmonary involvement on functional status, HRQoL, and fatigue in patients with SSc.

\section{PATIENTS AND METHODS}

Thirty-three patients ( 2 males, 31 females; mean age $46.2 \pm 13.4$ years; range 27 to 77 years) with a diagnosis of SSc (21 limited, 12 diffuse) according to the American Rheumatism Association criteria, and 34 healthy subjects (3 males, 31 females; mean age $40.9 \pm 12.8$ years; range 18 to 65 years) consented to participate in the study. All the patients were recruited from the department of rheumatology of Ankara University School of Medicine Hospital. The hospital's ethical committee approved the study. Each subject was performed a complete medical assessment including medical history, physical examination, and routine laboratory measurements.

Patients with significant comorbidities such as decompensated heart failure, uncontrolled blood pressure, significant renal insufficiency, cancer, fibromyalgia syndrome, psychiatric disorders, depression, respiratory infection, known histories of asthma, allergic alveolitis, thyroid diseases, or other systemic inflammatory rheumatic disease were excluded. All subjects underwent a standardized interview regarding their current medications, physical activity level, and smoking habits.

Resting spirometric measurements including forced vital capacity (FVC), vital capacity (VC), and maximum voluntary ventilation (MVV) were performed on a hand-held spirometer (Sensormedix, Vmax29, Yorba Linda, CA, USA) in a sitting position. Each subject performed at least three trials, and the best performance was used for analysis. Measurements were expressed as percentages of the normal predicted values. Eighty percent of predicted maximum or higher was accepted as normal. Clinical subsets of FVC were determined according to the American Thoracic Society guidelines for mild $(>70 \%$ of predicted), moderate (50-70\% of predicted), and severe $(<50 \%$ of predicted) physiologic impairment. ${ }^{8,11}$

Parenchymal abnormalities were identified by high resolution computed tomography (HRCT). HRCT grading included: 0, normal; I, ground glass appearance more than reticular; II, equal ground glass and reticular areas; III, reticular area more than ground glass; and IV, diffuse honeycomb lesions. ${ }^{12}$

Pulmonary hypertension was measured by the pulmonary artery systolic pressure which was calculated from the echocardiogram as systolic pulmonary artery pressure $=4 \mathrm{x}$ tricuspid regurgitation velocity ${ }^{2}+$ right atrial pressure..$^{13}$ Up to $25 \mathrm{mmHg}$ at rest was accepted as normal. ${ }^{1,6}$ A 0-100 mm breathing visual analog scale was used to measure self-assessment of breathlessness. ${ }^{1,3,8}$

Fatigue severity scale was used to measure the impact of excessive fatigue on daily function. ${ }^{14}$ The scale includes nine questions related to how fatigue interferes with certain activities, and rates its severity. The items are scored on a seven point scale including $1=$ strongly disagree, and $7=$ strongly agree. The scale was scored using mean of all the scores with minimum score being 1 and maximum score being 7 . 
The Medical Outcomes Study Short Form 36 questionnaire (Turkish version) was used to measure quality of life. ${ }^{16}$ The SF-36 includes one multi-item scale which assesses eight health concepts: physical functioning, role limitationsphysical, bodily pain, general health, vitality, social functioning, role limitations-emotional, and mental health. SF-36 scales are standardized to a range from 0 to 100 with a higher score indicating better health status. The validity and reliability study of the Turkish version of SF-36 has been well documented.

Health Assessment Questionnaire Disability Index was used to measure functional status. ${ }^{17}$ This index is a patient oriented functional assessment tool used to measure functional status by assessing the activity of living over the past week. It questions eight dimensions including dressing and grooming, arising, eating, walking, hygiene, reach and grip. Difficulty is rated on a four point scale. The scale has been validated in SSc.

\section{Statistical analysis}

For the continuous variables, the groups were compared using the t-test for the independent samples. The Mann-Whitney $U$ test was also employed to compare groups for with inhomogeneous distributed values. The relationships between pulmonary functions and patients' demographic and clinical variables were analyzed using the Pearson correlations coefficients for continued variables whereas Chisquare test was used for categorical variables.
Multiple regression analysis was used to investigate clinical and pulmonary factors affecting functional status, HRQoL, and fatigue. Data were analyzed using SPSS (SPSS Inc., Chicago, IL, USA) for Windows v.16.0. The level of statistical significance was set at $\mathrm{p}<0.05$.

\section{RESULTS}

In our sample, 12 patients (36.4\%) had diffuse SSc and 21 (63.6\%) had limited disease. Systemic disease was observed in 13 patients (39.4\%). The baseline characteristics of SSc patients and healthy controls are summarized in Table 1. There were no differences between the groups regarding age, sex, and body mass index. Table 2 and 3 show pulmonary findings of the patients and controls.

According to the clinical subsets of FVC, 8,11 nearly 27 patients (81\%) had normal to mild impairment in the FVC, with four (12\%) having moderate impairment, and two (6\%) having severe impairment. Also, 10 patients' (30\%) MVV was $<80$ of predicted. Means and standard deviations of fatigue severity scale, SF-36 subscales, and HAQ-DI score are presented in Table 4. Twenty-one patients (63\%) experienced severe fatigue over 5 point score. Table 5 shows the correlations between pulmonary functions and clinical/demographic parameters.

Regression analysis was conducted to investigate whether pulmonary involvement and respiratory muscle strength impact functional status, HRQoL, and fatigue. FVC, VC and MVV

Table 1. Demographic findings of patients and controls

\begin{tabular}{|c|c|c|c|c|c|c|c|c|c|}
\hline & \multicolumn{4}{|c|}{ Patients $(n=33)$} & \multicolumn{4}{|c|}{ Controls $(n=34)$} & \multirow[b]{2}{*}{$p$} \\
\hline & $\mathrm{n}$ & $\%$ & Mean \pm SD & Min.-Max. & $\mathrm{n}$ & $\%$ & Mean \pm SD & Min.-Max. & \\
\hline Age (years) & & & $46.2 \pm 13.4$ & $27-77$ & & & $40.9 \pm 12.8$ & $18-65$ & 0.103 \\
\hline \multicolumn{10}{|l|}{ Gender } \\
\hline Female & 31 & 93.9 & & & 31 & 91.2 & & & 0.577 \\
\hline Male & 2 & 6.1 & & & 3 & 8.8 & & & \\
\hline Body mass index & & & $25.6 \pm 5.7$ & $16.3-42.9$ & & & $26.8 \pm 3.5$ & $21.5-35.3$ & 0.298 \\
\hline Disease duration (years) & & & $7.03 \pm 5.9$ & $1.5-20$ & & & & & \\
\hline \multicolumn{10}{|l|}{ Smoking status } \\
\hline 1. user & 3 & 9.1 & & & 0 & 0 & & & \\
\hline 2. not user & 27 & 81.8 & & & 34 & 100 & & & \\
\hline 3. quit & 3 & 9.1 & & & 0 & 0 & & & \\
\hline Erythrocyte sedimentation rate & & & $25.4 \pm 17.5$ & $2-71$ & & & $15.1 \pm 10.3$ & 3-39 & 0.006 \\
\hline C-reactive protein & & & $2.2 \pm 2.1$ & $0.2-10.4$ & & & $0.7 \pm 0.6$ & $0.1-2.5$ & 0.001 \\
\hline Visual analog scale & & & $4.5 \pm 2.2$ & $0-9$ & & & $1.3 \pm 1.6$ & $0-5$ & 0.000 \\
\hline
\end{tabular}


Table 2. Pulmonary findings of patients

\begin{tabular}{|c|c|c|c|c|c|c|c|}
\hline & \multicolumn{7}{|c|}{ Patients $(n=33)$} \\
\hline & \multirow{2}{*}{$\frac{\text { Diffuse }}{\mathrm{n}}$} & \multirow{2}{*}{$\frac{\text { Limited }}{\mathrm{n}}$} & \multicolumn{2}{|c|}{ Total } & \multirow[b]{2}{*}{ Mean \pm SD } & \multirow[b]{2}{*}{ Median } & \multirow[b]{2}{*}{ Min.-Max } \\
\hline & & & $\mathrm{n}$ & $\%$ & & & \\
\hline \multicolumn{8}{|l|}{ High resolution computed tomography } \\
\hline Grade 0 & 1 & 3 & 4 & 12.1 & & & \\
\hline Grade I & 3 & 13 & 16 & 48.5 & & & \\
\hline Grade II & 4 & 1 & 5 & 15.2 & & & \\
\hline Grade III & 2 & 3 & 5 & 15.2 & & & \\
\hline Grade IV & 2 & 1 & 3 & 9.1 & & & \\
\hline Pulmonary arterial systolic pressure $(\mathrm{mmHg})$ & & & & & $25.5 \pm 4.7$ & & \\
\hline$>25(\mathrm{mmHg})$ & 4 & 8 & 12 & 36.4 & & & \\
\hline$\leq 25(\mathrm{mmHg})$ & 8 & 13 & 21 & 63.6 & & & \\
\hline Dyspnea & & & & & & 8 & $3-10$ \\
\hline
\end{tabular}

results of pulmonary function test were significant independent predictors of lower functional status in our patients $(\mathrm{Beta}=4.210, \mathrm{p}=0.033$; Beta= -4.844, $\mathrm{p}=0.028 ; \quad$ Beta $=-1.593, \quad \mathrm{p}=0.008$; respectively). Dyspnea was a significant predictor of higher fatigue (Beta $=0.716, \mathrm{p}=0.020)$. Pulmonary artery systolic pressure and MVV results of pulmonary function test were significant predictors of impaired physical component summary of HRQoL (Beta $=0.592, p=0.041$; Beta $=1.590, p=0.010$, respectively), and dyspnea was a significant independent predictor of mental component summary (Beta $=-0.661, p=0.038)$.

\section{DISCUSSION}

This study demonstrated that our SSc patients had lower functional status, HRQoL, and higher fatigue level compared to healthy controls. Respiratory muscle strength was a significant contributor to functional status and SF-36 physical component summary. Also, pulmonary arterial hypertension was a significant predictor of physical component summary of SF-36. Restrictive lung disease only contributed to functional status. Furthermore, dyspnea was a significant predictor of fatigue and mental component summary of SF-36, whereas HRCT had no significant contribution to functional status, fatigue, and SF-36.

It has been estimated that $40 \%$ patients with scleroderma have FVC of less than $75 \%$ predicted, indicating the presence of restrictive lung disease. The most rapid decline in FVC occurs within the first three to five years of disease onset. ${ }^{18}$

The strength of respiratory muscles can be evaluated from dynamic maneuvers such as the MVV. ${ }^{19,20}$ MVV is the largest volume which can be ventilated during a 10 to 15 seconds interval with voluntary effort. Average value for MVV was markedly reduced in our patients compared to healthy controls, and MVV of 10 patients (30\%) was $<80$ of predicted. In an unselected population of SSc patients for pulmonary involvement, this finding indicated that one third of our patients had evident respiratory muscle weakness.

Respiratory muscle function has been shown to contribute to dyspnea, exercise limitation,

Table 3. Pulmonary findings of patients and controls

\begin{tabular}{lccc}
\hline & Patients $(\mathrm{n}=33)$ & Controls $(\mathrm{n}=34)$ & $p$ \\
& Mean $\pm \mathrm{SD}$ & Mean $\pm \mathrm{SD}$ & \\
\hline Forced vital capacity & $2.7 \pm 0.6$ & $3.3 \pm 0.5$ & 0.000 \\
Forced expiratory volume in one second & $2.2 \pm 0.6$ & $2.7 \pm 0.5$ & 0.000 \\
Vital capacity & $2.7 \pm 0.6$ & $3.3 \pm 0.5$ & 0.000 \\
Maximum midexpiratory flow rate (25-75\%) & $2.4 \pm 1.03$ & $3.1 \pm 1.05$ & 0.011 \\
Peak expiratory flow rate & $4.9 \pm 1.5$ & $5,3 \pm 1.5$ & 0.351 \\
Maximum voluntary ventilation & $76.3 \pm 23.3$ & $97.4 \pm 22.4$ & 0.000 \\
\hline SD: Standard deviation. & & & \\
\hline
\end{tabular}


Table 4. Comparison of health related quality of life, functional status and fatigue level of patients and controls

\begin{tabular}{lcccccc}
\hline & \multicolumn{2}{c}{ Patients $(\mathrm{n}=33)$} & & \multicolumn{2}{c}{ Controls $(\mathrm{n}=34)$} \\
\cline { 2 - 3 } & Mean \pm SD & Min.-Max. & & Mean \pm SD & Min.-Max. & $p$ \\
\hline Fatigue severity scale & $4.8 \pm 1.8$ & $1.1-7$ & & $1.3 \pm 0.5$ & $1-3.1$ & .000 \\
SF-36 physical function & $40.1 \pm 11.2$ & $19.4-57.1$ & & $54.7 \pm 3.5$ & $44.6-57.1$ & .000 \\
Physical role & $39.5 \pm 13.8$ & $28-56.2$ & & $52.8 \pm 7.8$ & $28-56.2$ & .000 \\
Bodily pain & $42 \pm 11.2$ & $25.1-62.7$ & & $54.1 \pm 7.6$ & $37.5-62.7$ & .000 \\
General health & $41.3 \pm 10.3$ & $21.9-57.9$ & & $54.5 \pm 6.8$ & $36.8-62.6$ & .000 \\
Vitality & $41.3 \pm 11.9$ & $23-63.3$ & & $56.5 \pm 7.3$ & $44.3-70.4$ & .000 \\
Social function & $37.4 \pm 14.9$ & $13.7-57.1$ & & $51.5 \pm 6$ & $40.9-57.2$ & .000 \\
Emotional role & $38 \pm 16$ & $23.7-55.3$ & & $50.3 \pm 10.4$ & $23.7-55.3$ & .000 \\
Mental health & $33.2 \pm 14$ & $11.8-59.5$ & & $49.9 \pm 6$ & $39.1-64.1$ & .000 \\
Physical component summary & $40.7 \pm 9.2$ & $25.2-56.5$ & & $54.1 \pm 5.2$ & $39.4-59.6$ & .000 \\
Mental component summary & $37.5 \pm 12$ & $18-56.4$ & & $52.1 \pm 5.5$ & $38.4-61.7$ & .000 \\
Health Assessment Questionnaire Disability Index & $1.06 \pm 0.8$ & $0-2.7$ & & $0.0 \pm 0.1$ & $0-0.37$ & .000 \\
\hline SD: Standard deviation; Min.: Minimum; Max.: Maximum. & & & & & &
\end{tabular}

deconditioning and reduced HRQoL. ${ }^{21,22}$ Studies investigating respiratory muscle training have also reported significantly improved respiratory muscle strength and endurance, exercise capacity, dyspnea and HRQoL. ${ }^{23-26}$ Furthermore, trials in interstitial lung disease and pulmonary hypertension showed improved exercise capacity, symptoms and quality of life following pulmonary rehabilitation with or without respiratory muscle training. ${ }^{27-29}$ Marcisz et al. ${ }^{30}$ showed that FVC, forced expiratory volume in one second, VC, MVV, maximum midexpiratory flow rate $25-75 \%$, and peak expiratory flow rate values were significantly decreased in SSc patients compared to controls. Pulmonary function test results of our patients are similar to this study.

The HRCT is the most sensitive and specific modality for detecting and characterizing any interstitial lung disease. Being more sensitive than chest X-ray, it is the preferred imaging technique. ${ }^{18}$ A previous study in $\mathrm{SSc}$ patients reported no correlation between HRCT and HRQoL. ${ }^{9}$ Although we observed significant correlations between HRCT, functional status and some of the SF-36 subscales in our patients, HRCT was not a significant predictor of function and HRQoL in multivariate analysis.

Systemic sclerosis affects multiple physical, psychological, and social domains and is associated with impaired HRQoL. ${ }^{3,8,10}$

It has been reported that the greatest impairment in SF-36 subscale scores of SSc patients appeared to be in the physical functioning, general health, and role physical domains whereas mental health was relatively preserved., ${ }^{9,10}$ The authors suggested that this unexpected high result in mental summary score was due to psychological adaptation and coping with chronic and disabling underlying conditions.

In contrast with two studies in the literature,, 910 the present study showed that our patients had

Table 5. Correlations between pulmonary functions and clinical/demographic parameters

\begin{tabular}{|c|c|c|c|c|c|c|c|c|c|c|c|c|c|c|c|c|}
\hline & Age & $\begin{array}{l}\text { Disease } \\
\text { duration }\end{array}$ & ESR & VAS & $\begin{array}{c}\text { SF-36 } \\
\text { PF }\end{array}$ & $\mathrm{RP}$ & $\mathrm{BP}$ & $\mathrm{GH}$ & VT & SF & $\mathrm{RE}$ & $\mathrm{MH}$ & PCS & MCS & HAQ & FSS \\
\hline FVC & $-.453^{*}$ & $-.376^{*}$ & -.137 & .096 & .323 & -.049 & -.174 & .099 & -.107 & .043 & .051 & -.078 & .024 & .034 & $-.377^{*}$ & -.078 \\
\hline VC & $-.478^{*}$ & $-.445^{*}$ & -.115 & .005 & .352 & -.029 & -.119 & -.080 & -.086 & .072 & .054 & -.096 & .064 & .043 & $-.408^{*}$ & -.067 \\
\hline MVV & $-.559^{*}$ & $-.422 *$ & -.089 & -.103 & $.409^{*}$ & .147 & .007 & -.014 & -.027 & .002 & -. 004 & -.135 & .177 & .006 & -.284 & .085 \\
\hline Dyspnea & -.089 & -.321 & -.010 & $.325^{*}$ & $-.443^{*}$ & -.249 & $-.367^{*}$ & $-.315^{*}$ & $-.605^{* *}$ & $-.344^{*}$ & $-.341^{*}$ & $-.361^{*}$ & $-.419^{*}$ & $-.544^{* * *}$ & .302 & $.379^{*}$ \\
\hline PASP & $.405^{*}$ & $.498^{*}$ & .029 & -.156 & -. 026 & -. 025 & .217 & .036 & .285 & .027 & .029 & .205 & .053 & .139 & .111 & -.298 \\
\hline HRCT & .333 & $.389^{*}$ & .076 & .274 & $-.383^{*}$ & $-.383^{*}$ & -.194 & .028 & -.031 & $-.361^{*}$ & $-.345^{*}$ & .016 & -.316 & -.231 & $-.478^{*}$ & .131 \\
\hline
\end{tabular}


impaired mental health conditions in addition to impaired physical functions in comparison with the healthy controls. The discrepancy in terms of mental health reported in the previous studies can be explained by the differences in age, duration of the disease, level of education, employment history, degree of social support received, and cultural characteristics of the patients between the study populations.

Up to $50 \%$ of patients with SSc complain of dyspnea. Interstitial lung disease, airway disease, gastroesophageal reflux and recurrent aspiration, pulmonary hypertension and other conditions such as arthritis, obesity, anaemia, and/or deconditioning due to inactivity are the potential causes of dyspnea in these populations. ${ }^{5}$

Interstitial lung disease and dyspnea were also reported as significant contributors to function and HRQoL of SSc patients. ${ }^{5}$ Khanna et al. $^{8}$ showed significant univariate correlations between dyspnea and HAQ-DI and SF-36 in $\mathrm{SSc}$ patients with lung disease compared with healthy population. These previous studies ${ }^{5,8}$ reported that HRQoL and functional status were variably correlated with pulmonary involvement and dyspnea, and concluded that HAQ-DI and SF-36 should be included as outcome measures in interventions of scleroderma lung disease. In contrast with these studies, Chow et al. ${ }^{1}$ showed no significant correlations between functional status and lung involvement parameters such as pulmonary arterial hypertension, dyspnea, Carbon Monoxide Diffusing Capacity and FVC, and concluded that the HAQ-DI is of no value as an outcome measurement in SSc patients. In another study, no significant correlations were detected between SF-36 domains and lung involvement measured with HRCT and Carbon Monoxide Diffusing Capacity. ${ }^{9}$

Fatigue is a disabling symptom in $\mathrm{SSc}$ patients. It has been shown that the severity of gastrointestinal and joint involvement, perceived pain levels, presence of anti-U1-ribonucleoprotein antibodies, ineffective coping skills, dyspnea, low VC, poorer physical and social function, depressive symptoms, and sleep quality were associated with higher fatigue level in this population..$^{2-4}$

In this study, we demonstrated significant relationships between respiratory muscle strength, pulmonary involvement, functional status, HRQoL, and fatigue in SSc patients. Firstly, respiratory muscle strength and interstitial lung disease had significant predictive roles on functional status of our patients. Secondly, respiratory muscle strength, dyspnea and pulmonary hypertension were detected as significant contributors to HRQoL. Finally, dyspnea had a significant role on the severity of fatigue. To the best of our knowledge, our study is the first to assess the effects of respiratory muscle strength on functional status, fatigue, and HRQoL in patients with scleroderma.

Although our patients were not preselected for the presence of pulmonary involvement, we have determined during our study that $18 \%$ of our patients suffered from an evident interstitial lung disease, and $36.4 \%$ of them appeared to have pulmonary vessel involvement while 30\% had respiratory muscle weaknesses. Despite the presence of typical abnormalities in respiratory muscle function, lung parenchyma and pulmonary blood vessels, our patients did not report evident respiratory symptoms before and during the study. We suggest that dyspnea increases gradually and promotes a sedentary life style in SSc patients. Therefore, limited activity can mask respiratory impairment until increased demand appears as in chest infection or strenuous activities.

The current study had some limitations. First, MVV was used to measure respiratory muscle strength of the SSc patients. However, MVV is influenced not only by respiratory muscle strength, but also by the compliance of the lungthorax system, the condition of the ventilator control systems, and the resistance of both airways and tissues. Therefore, MVV was used in this study only as an indirect index of respiratory muscle strength, and the other factors should also be considered in the analysis of the results.

The second limitation was that our study was a cross-sectional design, and we have not investigated whether the long-term changes in pulmonary functions and muscle strength were associated with functional status, fatigue, and HRQoL. Finally, the sample size was relatively small, and the data was obtained from one clinic. Thus larger or multi-center studies are necessary in order to confirm our findings.

In conclusion; pulmonary involvement, respiratory muscle strength, functional status, 
HRQoL, and fatigue should be systematically measured in patients with $\mathrm{SSc}$ in the early course of the disease since there are significant relationships between these parameters. Once respiratory muscle weakness and pulmonary involvement are detected in this population with limited treatment options, a comprehensive pulmonary rehabilitation program including respiratory muscle exercises should be designed to improve functional status, HRQoL, and fatigue.

\section{Declaration of conflicting interests}

The authors declared no conflicts of interest with respect to the authorship and/or publication of this article.

\section{Funding}

The authors received no financial support for the research and/or authorship of this article.

\section{REFERENCES}

1. Chow S, Pope JE, Mehta S. Lack of correlation of the health assessment quastionnaire disability index in systemic sclerosis associated pulmonary arterial hypertension.Clin Exp Rheumatol 2008;26:1012-7.

2. Sandusky SB, McGuire L, Smith MT, Wigley FM, Haythornthwaite JA. Fatigue: an overlooked determinant of physical function in scleroderma. Rheumatology (Oxford) 2009;48:165-9.

3. Assassi S, Leyva AL, Mayes MD, Sharif R, Nair $\mathrm{DK}$, Fischbach $\mathrm{M}$, et al. Predictors of fatigue severity in early systemic sclerosis: a prospective longitudinal study of the GENISOS cohort. PLoS One 2011;6:e26061.

4. Ibn Yacoub Y, Amine B, Bensabbah R, Hajjaj-Hassouni $\mathrm{N}$. Assessment of fatigue and its relationships with disease-related parameters in patients with systemic sclerosis. Clin Rheumatol 2012;31:655-60.

5. Baron M, Sutton E, Hudson M, Thombs B, Markland $\mathrm{J}$, Pope $\mathrm{J}$, et al. The relationship of dyspnoea to function and quality of life in systemic sclerosis. Ann Rheum Dis 2008;67:644-50.

6. Van Laar JM, Stolk J, Tyndall A. Scleroderma lung. Pathogenesis, evaluation and current therapy. Drugs 2007;67:985-96.

7. Diot E, Boissinot E, Asquier E, Guilmot JL, Lemarie E, Valat C, et al. Relationship between abnormalities on high-resolution CT and pulmonary function in systemic sclerosis.Chest 1998;114:1623-30.

8. Khanna D, Clements PJ, Furst DE, Chon Y, Elashoff R, Roth $\mathrm{MD}$, et al. Correlation of the degree of dyspnea with health-related quality of life, functional abilities, and diffusing capacity for carbon monoxide in patients with systemic sclerosis and active alveolitis: results from the Scleroderma Lung Study. Arthritis Rheum 2005;52:592-600.

9. Del Rosso A, Boldrini M, D'Agostino D, Placidi GPA, Scarpato A, Pignone A, et al. Health-related quality of life in systemic sclerosis as measured by the Short Form 36: relationship with clinical and biologic markers.Arthritis Rheum 2004;51:475-81.

10. Hudson M, Thombs BD, Steele R, Panopalis P, Newton E, Baron M. Quality of life in patients with systemic sclerosis compared to the general population and patients with other chronic conditions. J Rheumatol 2009;36:768-72.

11. Behr J, Furst DE. Pulmonary function tests. Rheumatology (Oxford) 2008;47:65-7.

12. Gohari Moghadam K, Gharibdoost F, Parastandechehr G, Salehian P. Assessments of pulmonary involvement in patients with systemic sclerosis. Arch Iranian Med 2011;14:22-6.

13. Pyxaras SA, Pinamonti B, Barbati G, Santangelo S, Valentincic M, Cettolo F, et al. Echocardiographic evaluation of systolic and mean artery pressure in the follow-up of patients with pulmonary hypertension. Eur J Echocard 2011;12:696-701.

14. Krupp LB, La Rocca NG, Muir-Nash J, Steinberg AD. The fatigue severity scale. Application to patients with multiple sclerosis and systemic lupus erythmatodes. Arch Neurol 1989;46:1121-3.

15. Gencay-Can A, Can SS. Validation of the Turkish version of the fatigue severity scale in patients with fibromyalgia. Rheumatol Int 2012;32:27-31.

16. Dundar P, Fidaner C, Fidaner $\mathrm{H}$. Comparing the Turkish versions of WHOQOL-BREF and SF- 36, convergent validity of WHOQOL-BREF and SF-36. Hippokratia 2002;6:37-43.

17. Kuçuk Deveci AA, Sahin H, Ataman S, Griffiths $\mathrm{B}$, Tennant A. Issues in cross-cultural validity: example from the adaptation, reliability, and validity testing of a Turkish version of the Stanford Health Assessment Questionnaire. Arthritis Rheum 2004;51:14-9.

18. Scholand MB, Carr E, Frech T, Hatton N, Markewitz $\mathrm{B}$, Sawitzke A. Interstitial lung disease in systemic sclerosis: diagnosis and management. Rheumatology 2012;S1:008.

19. Neder JA, Andreoni S, Lerario MV, Nery LE. Reference values for lung function tests.II.Maximal respiratory pressures and voluntary ventilation. Braz J Med Biol Res 1999;32:719-27.

20. Ries AL. Theimportance of exercise in pulmonary rehabilitation. Clin Chest Med 1994;15:327-37.

21. Gosselink R, Houtmeyers E. Physiotherapy. European Respiratory Monograph 2000;13:70-89.

22. Kabitz HJ, Schwoerer A, Bremer HC, Sonntag F, Walterspacher S, Walker D, et al. Impairment of respiratory muscle function in pulmonary hypertension. ClinSci 2008;114:165-71.

23. Geddes EL, Reid WD, Crowe J, O'Brien K, Brooks D. Inspiratory muscle training in adults with chronic 
obstructive pulmonary disease: a systematic review. Respir Med 2005;99:1440-58.

24. Mereles D, Ehlken N, Kreuscher S, Ghofrani S, Hoeper MM, Halank M, et al. Exercise and respiratory training improve exercise capacity and quality of life in patients with severe chronic pulmonary hypertension. Circulation 2006;114:1482-9.

25. Crisafulli E, Costi S, Fabbri LM, Clini EM. Respiratory muscles training in COPD patients.Int $\mathrm{J}$ Chron Obstruct Pulmon Dis 2007;2:19-25.

26. Kabitz HJ, Bremer HC, Schwoerer A, Walterspacher $\mathrm{S}$, Walker DJ, Ehlken $\mathrm{N}$, et al. The combination of exercise and respiratory training improves respiratory muscle function in pulmonary hypertension. Lung 2014;192:321-8.
27. Holland AE, Wadell K, Spruit MA. How to adapt the pulmonary rehabilitation programme to patients with chronic respiratory disease other than COPD. Eur Respir Rev 2013;22:577-86.

28. Ferreira A, Garvey C, Connors GL, Hilling L, Rigler J, Farrell $\mathrm{S}$, et al. Pulmonary rehabilitation in interstitial lung disease: benefits and predictors of response. Chest 2009;135:442-7.

29. Garvey C. Interstitial lung disease and pulmonary rehabilitation. J Cardiopulm Rehabil Prev 2010;30:141-6.

30. Marcisz C, Kucharz EJ, Brzezinska-Wcislo L, Kotulska A, Jonderko G. Pulmonary functional abnormalities in asymptomatic patients with systemic sclerosis. Eur $\mathrm{J}$ Int Med 2003;14:162-5. 